\title{
elyra
}

\section{A mulher é: uma googlagem}

\section{Angélica Freitas}

No final de 2004, decidi pesquisar no Google o episódio em que o poeta Paul Verlaine pegou um revólver e deu um tiro na mão do poeta Arthur Rimbaud. Escrevi "Verlaine shot Rimbaud" - em inglês, porque ocorreriam mais resultados do que em português -, cliquei no primeiro link, li o texto, voltei à pesquisa, abri outro link. Os relatos contavam a mesma história, mas não da mesma maneira, claro. Num dos textos, inclusive, a data aparecia como 10 de julho de 1875; noutro, como 12 de julho de 1873. Pensei: e se juntasse isso num poema, com erros e tudo? Fui copiando $(C T R L+C)$ os trechos dos textos em que aparecia o momento do tiro e colando-os (CTRL+V) lado a lado, sem nem mesmo dar espaços, num arquivo do Word. Não mexi em nada. Chamei o resultado de "love (a collage)":

love (a collage)

During a drunken argument in Brussels, Verlaine shot atRimbaud, hitting him once in the wrist On 10 July 1875, in a drunken quarrel in Brussels, Verlaine shot Rimbaudin the wrist, and was imprisoned for two years at Mons. Together again in Brussels in the summer of that year, Verlaine shot Rimbaud in the wrist following a drunken argument. Verlaine, drunk and desolate, shot Rimbaud in the wristwith a $7 \mathrm{~mm}$ pistol after a quarrel. At one point, the tension between them became so great that Verlaine shot Rimbaud in the wrist. about 2 
o'clock, when M. Paul Verlaine, in his mother's bedroom, fired a shot of revolver. the subject of various books, films, and curiosities, ended July 12, 1873when a drunken Verlaine shot at Rimbaud and injured him in the wrist. Verlaine shot Rimbaud in a fit of drunken jealousy.

Fui montando mais poemas com o mecanismo de buscas e chamei o procedimento, meio que na brincadeira, de "googlagem": uma mistura de Google e colagem. Montei "A poesia não" depois de ficar curiosa sobre o que, segundo textos na internet, a poesia não era. A fartura de respostas e, mais tarde, a comicidade do conjunto me surpreenderam.

A poesia não é uma coisa idiota a poesia não é uma opção A poesia não é só linguagem a poesia, não

A poesia não é para ser entendida A poesia não é uma ciência exacta a poesia não é arma A poesia não é mais de Orfeu

A poesia não é diferente a poesia não é um casamento A Poesia não é um sentido a poesia não é, nunca foi

A poesia não é escolha

A poesia não é nem quer ser mercadoria

(Trecho de “A poesia não", publicado no blog “Tome uma xícara de chá” em 2005)

Enquanto escrevia meu segundo livro de poemas ("Um útero é do tamanho de um punho", editora Cosac Naify, 2012), que tinha a mulher como tema principal, decidi buscar na internet textos sobre o corpo feminino. Queria saber como eram escritos, com que palavras, com que autoridade. Um dia coloquei no Google "A mulher é" - vai que obtivesse alguma resposta interessante. Fui copiando e colando os resultados para talvez montar um poema mais tarde. Ao ler o material que havia juntado, percebi que nem fazia falta dar-lhe uma "ordem". Não havia como ficar menos ou mais absurdo do que aquilo. Permaneceu inédito. Foi um teste, o embrião da série "Três poemas com o auxílio do Google" ("A mulher vai", "A mulher quer", "A mulher pensa"), que acabou sendo publicada no livro. 


\section{A mulher é}

A mulher é uma obra de arte!

A MULHER É UMA SANTA GUERREIRA

A mulher é que cria o homem hipócrita!

A Mulher é que Manda

"A mulher é a chave da casa"

A mulher é mais forte que o homem e sobrevive muito mais facilmente à morte do cônjuge

A MULHER É UM GÊNERO HUMANO

A MULHER É UMA PAISAGEM

A mulher é o cara.

A mulher é complicada?

A mulher é toda sexualidade

A Mulher é um Show Programa comandado por Silvio Santos entre 1983 e 1986 na TVS/SBT

A MULHER É COMO UM LIVRO

A mulher é tratada com respeito no Brasil?

A mulher é frágil em força física e forte em artimanhas

A mulher é a obra superior de Deus

A Mulher é o Futuro do Homem

A Mulher é Amar

A Mulher é Submissa

A mulher é a responsável pela evolução do homem sapiens!

A mulher é como o Mundo

A mulher é a rainha do mundo e escrava de um desejo

A mulher é como a fruta

A mulher é um enigma

A mulher é um animal de cabelos longos e idéias curtas

A mulher é a grande empreendedora da Nova Classe Média

A mulher é o sexo forte, não somos nós

A mulher é um animal de tetas 
A mulher é seu útero

A mulher é volúvel, como pluma ao vento muda de acento e de pensamento

A mulher é o sexo frágil?

A mulher é ótima, por exemplo, na indústria de alimentação e é capaz também de fazer uma quentinha e distribuir

A mulher é, segundo ele, a origem de todo o mal do mundo

A mulher é a rainha do mundo e escrava de um desejo

A mulher é tao gente quanto o homem

A mulher e mais erotica que o homem

A mulher é uma flor que se estuda como a flor do campo

A mulher é a arca que Deus preparou para guardar o homem dos dilúvios da vida...!

A MULHER É FIEL?

A mulher é chamada de "Akeret Habayit" - a fundação do lar

A mulher é um flagelo para os inquisidores

A mulher é menos agressiva por natureza

A mulher é o mais sublime dos ideais

A mulher é filha da falsidade, sentinela do inferno, a inimiga da paz

A mulher é o instrumento de que se utiliza o diabo para ganhar as nossas almas

A mulher é a fonte do braço do diabo, e a sua voz é o chiado da serpente

A mulher é o ser que projeta a maior sombra ou a maior luz nos nossos sonhos

A mulher é o começo, meio e fim de nossas vidas

a mulher é um produtor absolutamente independente, da mesma forma que seu marido

A mulher é, portanto, um homem inferior

A mulher é fraca, o homem é forte, é sábio; mas a mulher é astuciosa e a ciência contra a astúcia nem sempre leva a melhor

A MULHER É A MÚSICA

A mulher é unicamente um objeto

A Mulher é uma Deusa 